\title{
Initial Experience Using the Transradial Approach for Endovascular Treatment of Vascular Pathologies: Safety and Feasibility
}

\author{
Giancarlo Saal-Zapata1] Rodolfo Rodríguez-Varela ${ }^{1}$ \\ ${ }^{1}$ Department of Neurosurgery, Hospital Nacional Guillermo Almenara \\ Irigoyen, La Victoria, Lima, Peru \\ Address for correspondence Giancarlo Saal-Zapata, MD, Hospital \\ Nacional Guillermo Almenara Irigoyen, Grau Avenue 800, La Victoria \\ 13, Lima, Peru (e-mail: gian_carlo1987@hotmail.com).
} J Neurosci Rural Pract 2022;13:123-128.

\begin{abstract}
Background Endovascular treatment of vascular pathologies through the transradial approach has been increasingly used and has demonstrated a low rate of complications.

Objective To report our initial experience in the endovascular treatment of cerebrovascular diseases with the transradial approach and to determine its safety and feasibility.

Methods Consecutive patients who underwent the transradial approach for endovascular treatment of aneurysms and vascular malformations were reviewed at a single institution. Technical success, fluoroscopy time, and access-related complications were analyzed.

Results Eight patients underwent endovascular treatment with the transradial approach. One arteriovenous fistula, one superficial temporal artery aneurysm, three arteriovenous malformations, and four aneurysms were treated successfully. The radial artery was successfully approached and a 6-F sheath was used in all the cases.

Keywords

- radial artery

- transradial

- embolization

- aneurysm

- arteriovenous malformation Navigation of guiding catheters ( 5 and 6 F) was done without complications. The most commonly approached artery was the right internal carotid artery, followed by the right vertebral artery. Postoperative vasospasm was identified in three patients. Mean fluoroscopy time was 34.7 minutes. Conversion to transfemoral approach was not required. No postoperative complications were reported.

Conclusions In our initial experience, the transradial approach is a safe and feasible alternative for the endovascular treatment of cerebrovascular pathologies.
\end{abstract}

\section{Introduction}

Several papers have demonstrated the benefits of the transradial approach (TRA) for the diagnosis and treatment of intracranial vascular pathologies. Patient satisfaction, lower access-site complications, and a shorter length of hospital stay are some benefits of the TRA over the classic transfemoral approach (TFA). ${ }^{1-3}$

The implementation of the TRA in therapeutic endovascular procedures has been reported with a low cross-over published online January 11,2022
DOI https://doi.org/

10.1055/s-0041-1742136. ISSN $0976-3147$. (c) 2022. Association for Helping Neurosurgical Sick People. All rights reserved.

This is an open access article published by Thieme under the terms of the Creative Commons Attribution-NonDerivative-NonCommercial-License, permitting copying and reproduction so long as the original work is given appropriate credit. Contents may not be used for commercial purposes, or adapted, remixed, transformed or built upon. (https://creativecommons.org/ licenses/by-nc-nd/4.0/)

Thieme Medical and Scientific Publishers Pvt. Ltd., A-12, 2nd Floor, Sector 2, Noida-201301 UP, India 
rates to TFA and low complication rates, allowing a safe and feasible treatment of intracranial vascular pathologies such as aneurysms, arteriovenous malformations (AVMs), carotid artery disease, arteriovenous fistulas (AVFs), and craniofacial tumors. ${ }^{4}$ On the other hand, the transition toTRA is somehow difficult to achieve due to the preferences of the TFA and the familiarity with this approach, requiring a consecutive number of procedures to master the technique. ${ }^{5-7}$

In addition, few papers reporting the TRA for treatment have been reported in Latin America, demonstrating that the transition to the TRA has certain limitations in some countries, especially in this region. ${ }^{8,9}$

Our study aimed to focus on the initial experience in the implementation of the TRA for the endovascular treatment of vascular pathologies and to determine its safety and feasibility.

\section{Methods}

Consecutive patients between January 2021 and March 2021 at our institution who underwent endovascular treatment with the TRA were selected and data were retrospectively collected. The Institutional Review Board approved the study and a signed informed consent was obtained prior to the procedures.

Age, sex, technical success of the radial artery (RA) puncture, navigation, and vessel catheterization were evaluated. Additionally, intra-arterial cocktail administration for vasospasm, size of the radial sheath, the type of catheter, the number of vessels catheterized, postoperative vasospasm, complications, and fluoroscopy times were also evaluated.

The selection of the TRA was based according to the decision of the treating neurosurgeon. All the cases were done by two operators (G.S.-Z. and R.R.-V.) with previous experience in TRA for diagnostic angiographies. The patients were treated under general anesthesia. The right arm and wrist were extended to bring the RA to the surface and then the wrist was sterilized and draped. The puncture technique of the RA was done without ultrasound guidance, following the double-wall puncture technique using a 21-gauge needle, and then, a 6-F sheath (Terumo, New Jersey, United States) was placed. A spasmolytic cocktail consisting of $2.5 \mathrm{mg}$ of verapamil, $200 \mu \mathrm{g}$ of nitroglycerine, and 3,000 IU of heparin were administered after hemodilution following the puncture of the RA. An initial angiogram of the RA was performed in all cases to visualize vasospasm, arterial anomalies, and the correct position of the sheath. Under road mapping, the guide catheter and wire were advanced into the target artery. The 5-F Simmons-2 catheter was formed in the ascending or descending aorta depending on the vessel to approach. Initially, a diagnostic angiogram with three-dimensional (3D) reconstruction was done with the 5-F Simmons catheter. After the vascular lesion was clearly defined, the Simmons catheter was left in the artery, or a 6-F guiding catheter (Envoy: Codman, United States; Benchmark: Penumbra, Alameda, California, United States) was used after exchange over a 260-cm hydrophilic wire. The rest of the embolization was performed according to the diagnosis. A control angiogram of the RA was done at the end of the procedure to identify vasospasm and administer an additional intra-arterial dose of verapamil if necessary. The radial sheath was removed and external compression with a band of gauze was applied over the puncture site for 24 hours.

\section{Results}

The TRA was employed in eight patients for the endovascular treatment of aneurysms and vascular malformations. One AVF, one superficial temporal artery aneurysm, three AVMs, and four intracranial aneurysms were successfully treated. Five patients (63\%) were male. The mean age was $45 \pm 18.9$ years. Three aneurysms were ruptured, whereas all the AVMs and the only AVF were ruptured. A summary of these cases is shown in -Table $\mathbf{1}$.

The RA was successfully catheterized in all cases; vasospasm was not reported after the 6-F sheath placement and no complications during navigation to the main arteries were reported. The 5-F Simmons-2 (Sidewinder; Terumo) guide

Table 1 Cases of endovascular treatment with the transradial approach

\begin{tabular}{|l|l|l|l|l|l|l|l|l|l|}
\hline Case & Age/sex & Diagnosis & Cocktail & $\begin{array}{l}\text { Sheath } \\
\text { (F) }\end{array}$ & Catheter & $\begin{array}{l}\text { Main } \\
\text { vessel }\end{array}$ & $\begin{array}{l}\text { PO } \\
\text { spasm }\end{array}$ & $\begin{array}{l}\text { Po } \\
\text { complication }\end{array}$ & $\begin{array}{l}\text { Fluoroscopy } \\
\text { time (min) }\end{array}$ \\
\hline 1 & $45 / \mathrm{M}$ & Cerebellar AVM & Yes & 6 & Envoy & R VA & No & No & 30.5 \\
\hline 2 & $48 / \mathrm{F}$ & Cerebellar AVF & Yes & 6 & Simmons & L VA & No & No & 47.3 \\
\hline 3 & $79 / \mathrm{M}$ & STA aneurysm & Yes & 6 & Simmons & R ECA & No & No & 25.1 \\
\hline 4 & $36 / \mathrm{M}$ & $\begin{array}{l}\text { PCom aneurysm } \\
\text { Paraclinoid aneurysm }\end{array}$ & Yes & 6 & Benchmark & R ICA & Yes & No & 44.3 \\
\hline 5 & $13 / \mathrm{F}$ & Temporal AVM & Yes & 6 & Simmons & R ICA & Yes & No & 70.9 \\
\hline 6 & $43 / \mathrm{M}$ & $\begin{array}{l}\text { Vertebral artery } \\
\text { aneurysm }\end{array}$ & Yes & 6 & Benchmark & R VA & No & No & 15.6 \\
\hline 7 & $38 / \mathrm{F}$ & Temporal AVM & Yes & 6 & Envoy & R ICA & No & No & 10.6 \\
\hline 8 & $58 / \mathrm{M}$ & AChoA aneurysm & Yes & 6 & Benchmark & L ICA & Yes & No & 33.4 \\
\hline
\end{tabular}

Abbreviations: AChoA, anterior choroidal artery; AVF, arteriovenous fistula; AVM, arteriovenous malformation; ECA, external carotid artery; F, female; ICA, internal carotid artery; L, left; M, male; PCom, posterior communicating; PO, postoperative; R, right; STA, superficial temporal artery; VA, vertebral artery. 
catheter was used for treatment in three cases, and in the rest of cases, a 6-F guide catheter (Benchmark or Envoy) was used after an exchange over a 260-cm hydrophilic wire without technical problems. Benchmark 071 (Penumbra) was the most commonly used catheter. The most frequently catheterized artery was the right internal carotid artery (ICA; three cases), followed by the right vertebral artery (two cases). In the four cases of vascular malformations, the liquid embolic agent, Squid 18 (Balt), was used, whereas for aneurysms treatment, coils, balloon-assisted coiling, and stenting were employed. No technical difficulties were reported during the embolization. The mean fluoroscopy time was 34.7 minutes. Three patients developed moderate angiographic vasospasm at the end of the procedure which required further intra-arterial verapamil administration which resolved with a new injection. Postoperative compli- cations were not reported. RA occlusion did not occur. Crossover to transfemoral approach was not required in our series. Two representative cases are described.

\section{Illustrative Cases}

\section{Case 1}

A 45-year-old male presented with headache, vomiting, and ataxia. Computed tomography (CT) scan revealed a cerebellar hematoma without brainstem compression, suggestive of a ruptured AVM. A diagnostic angiogram demonstrated a ruptured cerebellar AVM supplied by the right anterior superior cerebellar artery (ASCA). Endovascular treatment was proposed with the TRA. A 6-F radial sheath and a 6-F Envoy (Cordis) guiding catheter over a 0.035 -inch guide were navigated through the radial, brachial, and right vertebral
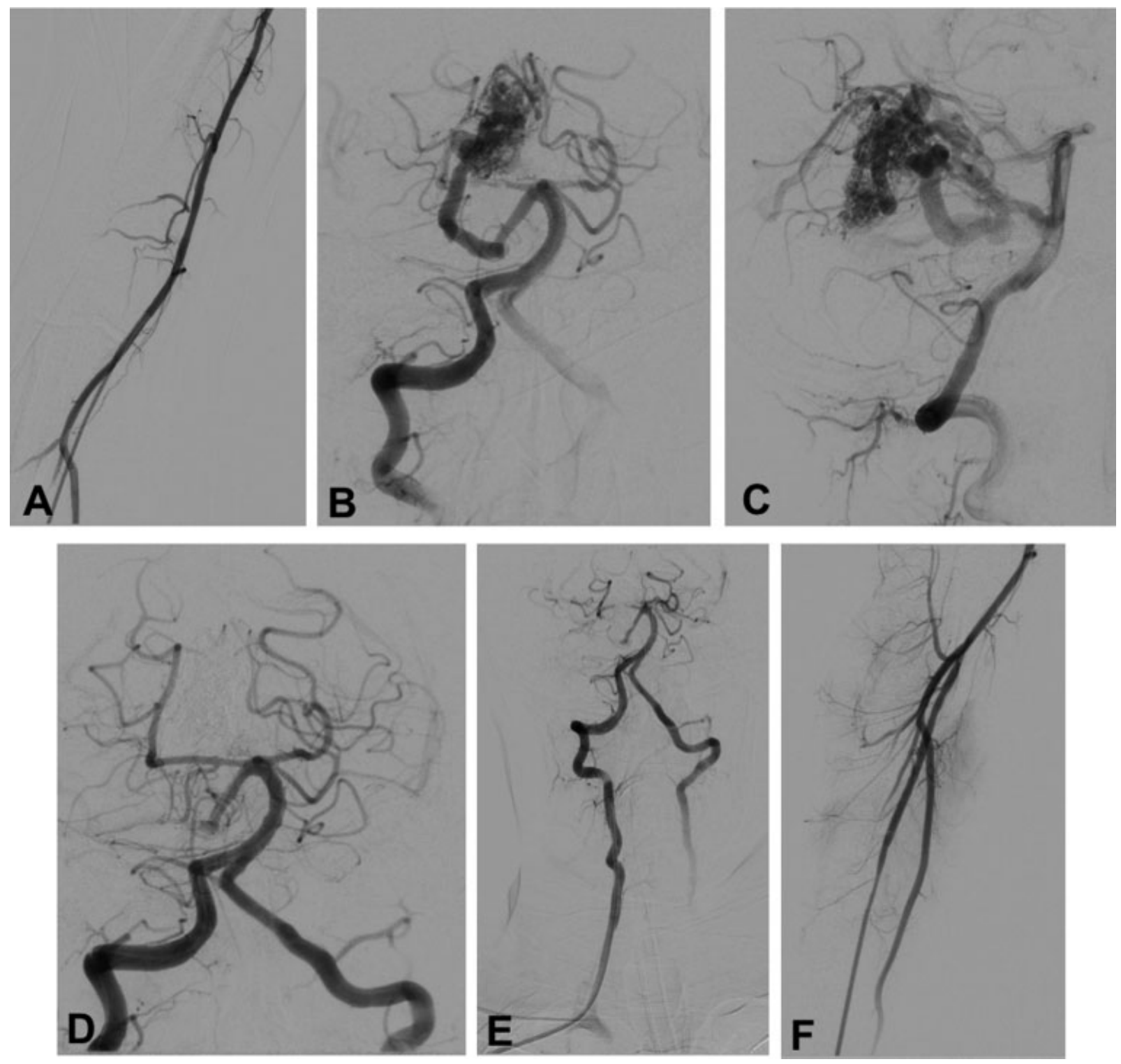

Fig. 1 (A) Radial artery angiography without spasm. (B, C) Frontal and lateral projections show the presence of a right cerebellar arteriovenous malformation supplied by the right anterior superior cerebellar artery. (D, E) Frontal view shows the complete obliteration of the arteriovenous malformation and the presence of the 6-F Envoy guiding catheter in the right vertebral artery. (F) Postoperative angiography does not show radial artery spasm. 
artery. Then, a Sonic microcatheter (Balt, Montmorency, France) was navigated over a 0.07-inch microguidewire into the ASCA and the nidus was completely obliterated with $5 \mathrm{~mL}$ of Squid 18. No postoperative RA vasospasm was noticed at the end of the procedure. No hematomas or vascular access complications were reported. The clinical evolution of the patient was uneventful. This case is shown in - Fig. 1.

\section{Case 2}

A 36-year-old male presented with sudden headache and a CT scan revealed subarachnoid hemorrhage. A CTA scan demonstrated two intracranial aneurysms located in the right ICA at the posterior communicating and paraclinoid segments, respectively. Endovascular treatment was decided. A 6-F radial sheath and the 5-F Simmons (Merit) guide catheter were used initially to perform a diagnostic angiogram. After the 3D reconstruction, catheter exchange over a $260-\mathrm{cm}$ wire was done and a 6-F Benchmark 071 guide catheter was placed in the right ICA. Coiling of the posterior communicating artery aneurysm and balloon-assisted coiling of the paraclinoid aneurysm were performed without complications. The catheters were withdrawn and a final angiogram of the RA showed vasospasm which required verapamil administration. No vascular access complications were reported. The clinical evolution of the patient was uneventful. This case is shown in - Fig. 2.

\section{Discussion}

The TRA has gained widespread acceptance among neurosurgeons and neurointerventionists due to its demonstrated safety and efficacy for treatment of neuroendovascular procedures. ${ }^{4-7,10}$ Despite a substantial learning curve is mandatory and requires 30 to 50 angiographies to master the technique, ${ }^{11}$ several advantages over the classic TFA have been reported such as patient satisfaction, lower morbidity, and less hospital length of stay. ${ }^{3}$ In this initial experience, we demonstrated that this approach is safe and feasible and permitted an appropriate treatment of intracranial aneurysms and vascular malformations without access-related complications and without catheter navigation-related difficulties.

Previous papers evaluated the TRA based on different steps such as the cannulation of the RA, the navigation across the aortic arch, the navigation into the artery of interest, and distal access or the utilization of additional devices, for example, microcatheters. ${ }^{10-12}$ Our results are in accordance with these steps and all of them were accomplished successfully.

Although these were the first eight cases in our experience, no technical problems were reported during the puncture of the radial artery despite ultrasound was not employed as a usual practice in our institution, although its utilization demonstrated lower access site complications. ${ }^{13}$ Manual palpation and cannulation of the RA is our standard practice, as well as in the cases of TFA.
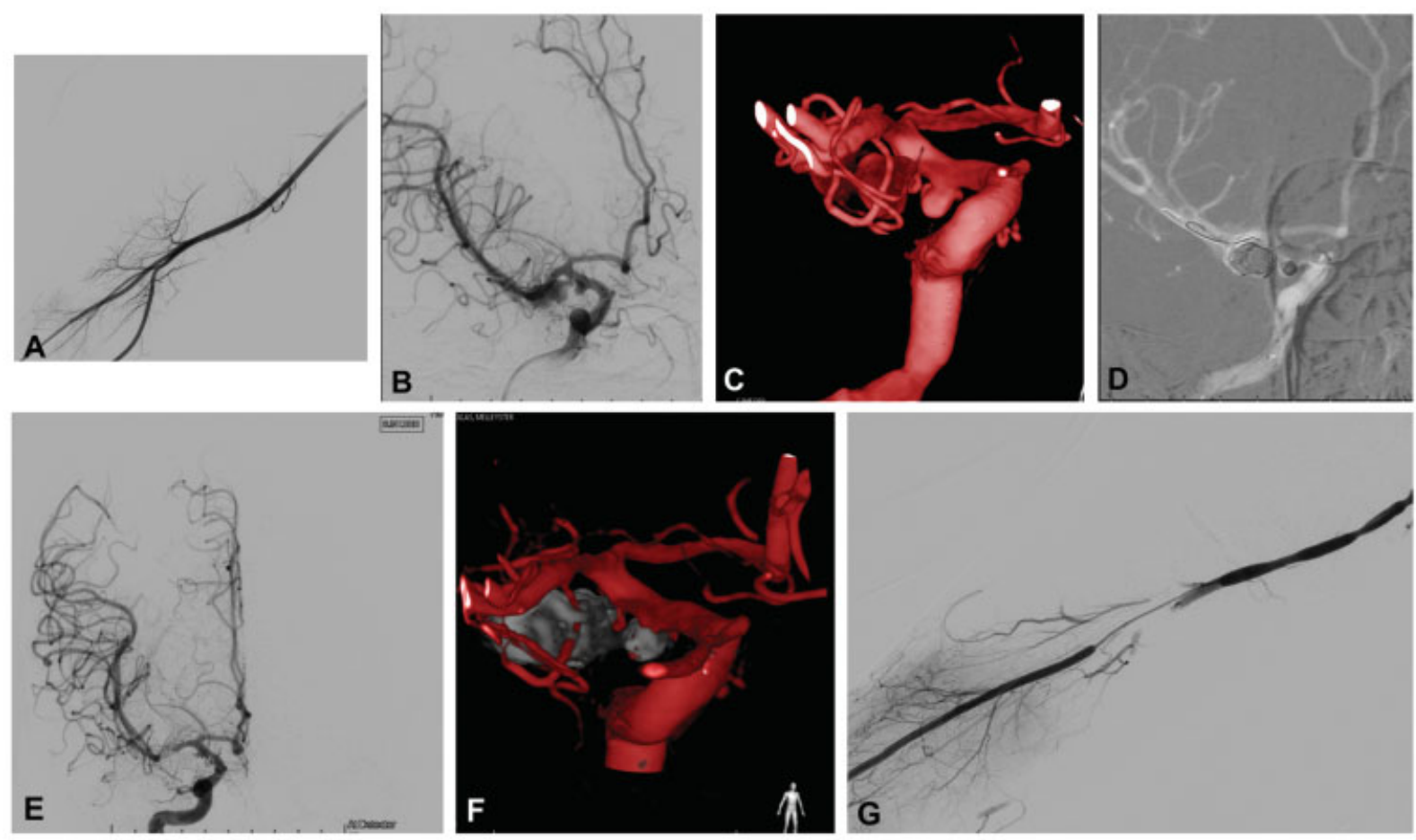

Fig. 2 (A) Radial artery angiography without spasm. (B, C) Oblique projection of the right internal carotid artery with three-dimensional reconstruction shows a ruptured posterior communicating aneurysm and an unruptured paraclinoid aneurysm. (D) Road mapping shows the treatment of both aneurysms using coils and balloon-assisted coiling. (E) Frontal view shows the complete obliteration of both aneurysms with an adequate filling of distal vessels. (F) Postoperative three-dimensional reconstruction of both aneurysms. (G) Postoperative spam of the radial artery which required intra-arterial administration of verapamil. 
In five cases, we initially used the 5-F Merit or 5-F Terumo/Sidewinder Simmons 2 catheters to navigate into the selected artery and then, perform an exchange of catheters to navigate a 6-F Benchmark or a 6-F Envoy guide catheter. During this maneuver, with the purpose to obtain an adequate catheter support, a 0.035-inch guidewire was advanced either to the external carotid artery or to the petrous segment of the ICA. After this step was accomplished, the embolization was done according to the type of vascular lesion. Embolic agents, coils, balloons, and stents were successfully employed without technical difficulties during the navigation of microcatheters. Previous papers described the exchange of catheters as a feasible option when longer intermediate catheters were not available. ${ }^{9}$ In three cases, we embolized through the Simmons 5-F guiding catheter which provided enough support to advance into the artery of interest and avoid kinking. In these cases, a detachable tip microcatheter was used (Sonic 1.5F; Balt, Montmorency, France). The navigation of a 6-F Benchmark 071 (Penumbra) guide catheter accompanied by the 5F Select Simmons (Penumbra) catheter is an ideal combination to gain access to the selected intracranial arteries without catheter exchange. ${ }^{6,10}$ However, the Select Simmons catheter is not available in our institution.

Regarding radial artery occlusion (RAO) and radial artery spasm (RAS), which account for up to 10 and $30 \%$, respectively, ${ }^{14}$ they were not recorded in our series. A recent metaanalysis reported an incidence of $1.88 \%$ for RAO when endovascular treatments were performed. ${ }^{4}$ This was not a concern at the beginning of the procedures due to the administration of an intra-arterial spasmolytic cocktail consisting of verapamil, nitroglycerine, and heparin, as previously described. The utilization of this cocktail demonstrated the reduction in the incidence of RAO and RAS. ${ }^{15,16}$ Failure to perform the TRA due to RAS was very low in recent studies, ${ }^{7}$ very similar to our results which reported no cases at the beginning of the procedure and three cases of vasospasm at the end of the procedure which reversed with the intraarterial administration of $2.5 \mathrm{mg}$ of verapamil. The crossover rate to TFA reported in a meta-analysis was $4.77 \%$, and this occurred due to the inability to access the RA or to catheterize the target vessel. ${ }^{4}$ In our series, we did not experience shifts to TFA due to the $100 \%$ technical success in approaching the RA and navigating the catheter into the target vessel.

Few Latin-American experiences with the TRA have been reported. Goland et al published a series of 40 intracranial aneurysms treated successfully with the TRA using coils and flow diverters. ${ }^{8}$ This experience was the first reported in LatinAmerica. The same author, later on published the experience in the treatment of 50 and 59 aneurysms, respectively. ${ }^{9,17}$ No other papers related to TRA were found in this region.

Other alternatives for diagnostic and therapeutic TRA have been reported, such as the distal transradial approach (dTRA), in which the RA is approached in the anatomical snuffbox. ${ }^{18-20}$ The advantage of this approach is the preservation of the superficial palmar arch to reduce the risk of RAO.

\section{Limitations}

One of the main limitations of the study is the small sample and the lack of a comparison between the TRA and TFA which did not allow to draw conclusive results. However, this study was made to determine the safety and feasibility of the TRA in an initial experience of neurointerventions. The lack of follow-up does not allow to report the patency of the RA; nevertheless, this was due to the recent development of this technique in our institution.

\section{Conclusion}

The TRA is a safe and feasible alternative route to treat vascular pathologies endovascularly without access-related complications. A previous experience performing the TRA in cases of diagnostic angiographies is mandatory to perform therapeutic procedures.

\section{Funding \\ None. \\ Conflict of Interest \\ None declared.}

\section{References}

1 Snelling BM, Sur S, Shah SS, Marlow MM, Cohen MG, Peterson EC. Transradial access: lessons learned from cardiology. J Neurointerv Surg 2018;10(05):487-492

2 Snelling BM, Sur S, Shah SS, et al. Transradial cerebral angiography: techniques and outcomes. J Neurointerv Surg 2018;10(09): 874-881

3 Wang Z, Xia J, Wang W, et al. Transradial versus transfemoral approach for cerebral angiography: a prospective comparison. J Interv Med 2019;2(01):31-34

4 Joshi KC, Beer-Furlan A, Crowley RW, Chen M, Munich SA. Transradial approach for neurointerventions: a systematic review of the literature. J Neurointerv Surg 2020;12(09):886-892

5 Almallouhi E, Leary J, Wessell J, et al. Fast-track incorporation of the transradial approach in endovascular neurointervention. J Neurointerv Surg 2020;12(02):176-180

6 Goldman DT, Bageac D, Mills A, et al. Transradial approach for neuroendovascular procedures: a single-center review of safety and feasibility. AJNR Am J Neuroradiol 2021;42(02):313-318

7 Chivot C, Bouzerar R, Yzet T. Transitioning to transradial access for cerebral aneurysm embolization. AJNR Am J Neuroradiol 2019;40 (11):1947-1953

8 Goland J, Doroszuk GF, Garbugino SL, Ypa MP. Transradial approach to treating endovascular cerebral aneurysms: case series and technical note. Surg Neurol Int 2017;8:73

9 Goland J, Doroszuk G. Transradial approach for endovascular diagnosis and treatment of ruptured cerebral aneurysms: A descriptive study. Surg Neurol Int 2019;10:87

10 Sattur MG, Almallouhi E, Lena JR, Spiotta AM. Illustrated guide to the transradial approach for neuroendovascular surgery: a stepby-step description gleaned from over 500 cases at an early adopter single center. Oper Neurosurg (Hagerstown) 2020;19 (02):181-189

11 Zussman BM, Tonetti DA, Stone J, et al. Maturing institutional experience with the transradial approach for diagnostic cerebral arteriography: overcoming the learning curve. J Neurointerv Surg 2019;11(12):1235-1238 
12 Zussman BM, Tonetti DA, Stone J, et al. A prospective study of the transradial approach for diagnostic cerebral arteriography. J Neurointerv Surg 2019;11(10):1045-1049

13 Seto AH, Roberts JS, Abu-Fadel MS, et al. Real-time ultrasound guidance facilitates transradial access: RAUST (Radial Artery access with Ultrasound Trial). JACC Cardiovasc Interv 2015;8 (02):283-291

14 Brunet M-C, Chen SH, Peterson EC. Transradial access for neurointerventions: management of access challenges and complications. J Neurointerv Surg 2020;12(01):82-86

15 Pancholy SB. Comparison of the effect of intra-arterial versus intravenous heparin on radial artery occlusion after transradial catheterization. Am J Cardiol 2009;104(08):1083-1085

16 Kwok CS, Rashid M, Fraser D, Nolan J, Mamas M. Intra-arterial vasodilators to prevent radial artery spasm: a systematic review and pooled analysis of clinical studies. Cardiovasc Revasc Med 2015;16(08):484-490

17 Goland J, Doroszuk G, Garbugino S, Ypa P, Fuertes F. Tratamiento endovascular de aneurismas por abordaje radial. 50 casos. Técnica y resultados. Rev Argent Neurocir 2017;31:29-34

18 Patel P, Majmundar N, Bach I, et al. Distal transradial access in the anatomic snuffbox for diagnostic cerebral angiography. AJNR Am J Neuroradiol 2019;40(09):1526-1528

19 Weinberg JH, Sweid A, Khanna O, et al. Access through the anatomical snuffbox for neuroendovascular procedures: a single institution series. Oper Neurosurg (Hagerstown) 2020;19(05): 495-501

20 Brunet M-C, Chen SH, Sur S, et al. Distal transradial access in the anatomical snuffbox for diagnostic cerebral angiography. J Neurointerv Surg 2019;11(07):710-713 